\title{
Automating Partial Period Bond Valuation With Excel's Day Counting Functions
}

David Vicknair, DBA, Rockhurst University, USA

James Spruell, PhD, Rockhurst University, USA

\begin{abstract}
An Excel model for calculating the actual price of bonds under a 30 day/month, 360 day/year day counting assumption by nesting the DAYS360 function within the PV function is developed. When programmed into an Excel spreadsheet, the model can accommodate annual and semiannual payment bonds sold on or between interest dates using six fundamental inputs, including the bond's par value, maturity date, annual stated rate of interest, and payment frequency, the annual market rate of interest, and the settlement date. Thus, the model can be applied across the business curriculum in a variety of introductory and more advanced level courses.
\end{abstract}

\section{INTRODUCTION}

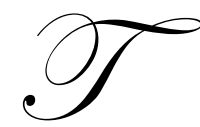

the PV function (substituting terms for rate, nper, pmt and fv, respectively): ${ }^{1}$

$=\mathrm{PV}(\mathrm{Y} / \mathrm{M}, \mathrm{N},-\mathrm{P} * \mathrm{R} / \mathrm{M},-\mathrm{P})$

where,

\begin{tabular}{|r|l|}
\hline $\mathrm{Y}=$ & annual market rate (as a decimal) \\
\hline $\mathrm{M}=$ & number of interest payments per year \\
\hline $\mathrm{P}=$ & bond's par or maturity value \\
\hline $\mathrm{N}=$ & number of remaining interest payments after the settlement date \\
\hline $\mathrm{R}=$ & annual stated rate (as a decimal) \\
\hline
\end{tabular}

However, when the settlement date falls between interest payment dates, equation (1) must be modified to incorporate an additional term, alpha $(\alpha)$, which represents the fraction of the current interest period that has elapsed prior to the settlement date (e.g., the number of days between the previous interest payment date and the settlement date divided by the total number of days in the current interest period): ${ }^{3}$

\footnotetext{
${ }^{1}$ The PV function has the syntax =PV(rate,nper,pmt,fv,type), where rate=the interest rate per period, nper=the total number of payment periods in an annuity, pmt=the fixed payment over the life of the annuity, $f v=$ future cash value and type $=$ the number 0 or 1 indicating when annuity payments are due $(0=$ end of period, $1=$ begin of period). The type argument is ignored throughout the paper because bond interest payments are in the form of an ordinary annuity and type has a default value of " 0 ".

${ }^{2}$ In the case of a callable bond, $\mathrm{P}$ equals the expected redemption value. The focus of this paper is noncallable bonds and so a redemption value other than par value is ignored.

${ }^{3}$ The core term in equation (2), =PV(Y/M,-P*R/M,-P), is defined as the present value of the bond's cash flows discounted to the beginning of the current interest period at the appropriate market rate of interest. Rusbarsky and Vicknair (1999) describe equation (2) as a two step process and explain (ftn 8) why the correct value cannot be obtained simply by substituting a noninteger value for $\mathrm{N}$ into equation (1).
} 
$=\mathrm{PV}(\mathrm{Y} / \mathrm{M},-\mathrm{P} * \mathrm{R} / \mathrm{M},-\mathrm{P}) *(1+\mathrm{Y} / \mathrm{M})^{\wedge} \alpha$

The values of $\mathrm{Y}, \mathrm{M}, \mathrm{P}$ and $\mathrm{R}$ are easily inferred from the bond itself or from the problem narrative. In contrast, the value of $\mathrm{N}$ is generally inferred from the settlement date and maturity date timeline considering the number of interest payments per year (M) using pencil and paper techniques. The calculation of $\alpha$ is problematic because it depends on the particular day counting convention required by the National Association of Securities Dealers (NASD) or the Municipal Securities Rulemaking Board (MSRB). ${ }^{4}$

Because of these difficulties, undergraduate accounting and finance textbooks generally limit bond valuation illustrations and examples to bonds sold on interest payment dates where an equation (1) type model is used exclusively. As a result, most business students graduate without having been exposed to equation (2) and the practical reality that bonds may be traded on any day the markets are open.

This paper demonstrates how to incorporate basic date counting into equation (2) for a generic annual payment or semiannual payment bond assuming the same 30-day month, 360-day year (30/360) date counting convention (US/NASD method) used by US corporate bonds and many US agency issues. Under a 30/360 convention, both $\mathrm{N}$ and $\alpha$ can be easily inferred from the settlement date, maturity date and number of interest payments in a year $(\mathrm{M})$.

The paper begins with a general discussion of 30/360 day counting and then develops the Excel syntax for calculating $\mathrm{N}$ and $\alpha$ using Excel's DAYS360 function. The paper then provides a spreadsheet for calculating the actual price of an annual or semiannual payment bond by nesting DAYS360 syntax into equation (2). The resulting spreadsheet requires the same six variables regardless whether the bond pays interest annually or semiannually and is sold on or between interest payment dates. Thus, the spreadsheet is applicable to bond valuation across the curriculum.

\section{OVERVIEW OF 30/360 DAY COUNTING}

In the context of bond valuation, the objective of day counting is to find the number of days (a) between the settlement date and maturity date and (b) between the settlement date and the next interest date (or between the previous interest date and the settlement date). The algorithm for finding the number of 30/360 days (US/NASD method $)^{5}$ between two dates can be expressed as follows:

$N O D=(Y r 2-Y r 1) \times 360+(M t h 2-M t h 1) \times 30+($ Day $2-$ Day 1$)$

where,

\begin{tabular}{|r|l|}
\hline NOD $=$ & number of $30 / 360$ days between two dates \\
\hline Yr $=$ & year \\
\hline Mth $=$ & month of year (January $=1$ ) \\
\hline Day $=$ & day of month (coded 30 whenever Day1 or Day2 is the last day of the month) \\
\hline $1=$ & earlier date \\
\hline $2=$ & later date \\
\hline
\end{tabular}

For example, assume that a bond with a maturity date of August 15, 2011 which pays interest semiannually on August 15 and February 15 is sold on December 18, 2007. The previous interest date (the beginning of the current interest period) fell on August 15, 2007. Using equation (3), there are 1,317 [(2011-2007) $\times 360+(8$ -

\footnotetext{
${ }^{4}$ Day-counting rules are found in NASD Uniform Practice Code, Section 46 and MSRB Rule G-33. Both sets of rules are described in Mayle (1993, 17-23, A3-A15).

${ }^{5}$ Under the alternative European method (ignored here) starting and ending dates that occur on the $31^{\text {st }}$ day of the month are coded 30. For example, under the US/NASD method there are 30 days between March 1 and March 31, while under the European method there are only 29 days.
} 
12) $\times 30+(15-18)$ ] days between December 18, 2007 (settlement date) and August 15, 2011 (maturity date). Likewise, there are $123[(2007-2007) \times 360+(8-12) \times 30+(18-15)]$ days between August 15, 2007 (previous interest date) and December 18, 2007 (settlement date).

Solving for NOD with equation (3) can be tedious and so using a date counting function such as DAYS360 makes practical sense. Assuming the US (NASD) approach, DAYS360 has the following syntax, where start_date and finish_date are the two dates between which you want to know the number of days: ${ }^{6}$

=DAYS360(start_date,finish_date)

DAYS360 is robust and so start_date and finish_date can be references to cells with dates, dates in quotes, or serial date numbers in quotes. For example, the number of days between December 18, 2007 and February 15, 2008 can be expressed as =DAYS360(“12/18/2007","2/15/2008”) or =DAYS360(“39434","39493"). Likewise, the number of days between December 15, 2008 and August 15, 2011 can be expressed as

=DAYS360(“12/18/2007","8/15/2011”) or =DAYS360(“39434","40770”).

\section{DETERMINING N}

The number of remaining interest payments after settlement $(\mathrm{N})$ under 30/360 day counting can be determined from the settlement date (settlement_date=first_date), maturity date (maturity_date=second_date) and number of days in the period in which the settlement date falls (NOPD): ${ }^{8}$

=ROUNDUP(DAYS360(settlement_date,maturity_date)/NOPD,0)

Equation (4) essentially calculates N in three steps. In step one DAYS360 determines the number of 30/360 days between the settlement date and maturity date. In step two, the number of days is converted into the equivalent number of periods by dividing the number of days by NOPD. Because 30/360 assumes that each month has 30 days, NOPD is inferred from the number of interest payments per year $(M)$ : if $M=1$, then $N O P D=360$; if $M=2$, then $\mathrm{NOPD}=180 .^{9}$

Table A

Interest Periods After Settlement Versus Interest Payments After Settlement

\begin{tabular}{|l|l|l|}
\hline Number & \multicolumn{1}{|c|}{ Interest Period } & \multicolumn{1}{|c|}{ Interest Payment } \\
\hline .367 & December 18, 2007-February 15, 2008 & na \\
\hline 1 & February 14, 2008-August 15,2008 & February 15, 2008 \\
\hline 2 & August 15, 2008-February 15, 2009 & August 15, 2008 \\
\hline 3 & February 15, 2009-August 15, 2009 & February 15, 2009 \\
\hline 4 & August 15, 2009-February 15, 2010 & August 15, 2009 \\
\hline 5 & February 15,2010-August 15, 2010 & February 15, 2010 \\
\hline 6 & August 15, 2010-February 15, 2011 & August 15, 2010 \\
\hline 7 & February 15, 2011-August 15, 2011 & February 15, 2011 \\
\hline 8 & na & August 15, 2011 \\
\hline
\end{tabular}

It is important here to distinguish between the number of interest periods after settlement (NOD/NOPD) and the number of interest payments after settlement $(\mathrm{N})$. When a bond is sold between interest dates, step 2 returns

\footnotetext{
${ }^{6}$ When the European method is desired, the syntax for DAYS360 is: =DAYS360(start_date,finish_date,True)

${ }^{7}$ Serial date numbers can be found by entering the date into a cell in date format (for example, $\mathrm{mm} / \mathrm{dd} / \mathrm{yyyy}$ ) and formatting the cell to a general number format or by using DATEVALUE.

8 Alternatively, the number of interest payments could be calculated by using ROUNDDOWN: $=1+$ ROUNDDOWN(DAYS360(“settlement_date","maturity_date")/180,0).

${ }^{9}$ Later in the paper, NOPD is determined from $\mathrm{M}$ with a logical IF statement.
} 
a noninteger. For example, assuming maturity_date=August 15, 2011, settlement_date=December 18, 2007 and $\mathrm{M}=2$ (thus, NOPD=180), the number of remaining interest periods is 7.3167 [=DAYS360("1/18/2007","8/15/2011")/180]. As demonstrated in Table A, although there are 7.3167 interest periods after the settlement date there are actually eight interest payments after the settlement date. Thus the third step simply uses ROUNDUP to convert (round up) 7.3167 remaining interest periods to 8 remaining interest payments $(\mathrm{N})$.

\section{DETERMINING ALPHA $(\alpha)$}

There are two approaches for determining $\alpha$. The first approach finds $\alpha$ directly by dividing the number of days between the prior interest date (prior_interest_date) and the settlement date by NOPD: ${ }^{10}$

=DAYS360(prior_interest_date,settlement_date)/NOPD

The second approach derives $\alpha$ from the same information used previously to find $\mathrm{N}$ (settlement_date, maturity_date and NOPD) as the fraction which remains after subtracting the number of remaining interest payments after settlement $(\mathrm{N})$ from the remaining interest periods after settlement (NOD/NOPD):

$=$ ROUNDUP(DAYS360(settlement_date,maturity_date)/NOPD,0)

-DAYS360(settlement_date,maturity_date)/NOPD)

Arguably, equation (6) is more intuitive than equation (7), assuming students have no difficulty inferring the prior interest date. However, equation (6) does raise the number of input variables by one (prior_interest_date) and forces the instructor to incorporate payment date information (e.g., the bond pays interest annually on August 15 and February 15) rather than simply noting that the bond pays interest semiannually, otherwise students would have to infer the second interest date from the maturity date (e.g., February 15 is 180 days from August 15).

In contrast, equation (7) is somewhat more difficult to program, but does not require an additional date. We feel that equation (7) should pose little difficulty to students who understand the distinction between the number of remaining interest periods and $\mathrm{N}$ shown in Table $\mathrm{A}$. Thus, we use equation (7) to develop the complete model below

\section{AN EXAMPLE BOND}

By nesting equations (5) and (7) within equation (2), the following bond valuation models can be developed for semiannual and annual payment bonds, respectively

=PV(Y/M, (ROUNDUP(DAYS360(settlement_date,maturity_date)/180,0),-P*R/M, $-\mathrm{P})^{*}(1+. \mathrm{Y} / \mathrm{M})^{\wedge}($ ROUNDUP(DAYS360(settlement_date,maturity_date)/180,0)

-DAYS360(settlement_date,maturity_date)/180)

$=\mathrm{PV}(\mathrm{Y} / \mathrm{M},($ ROUNDUP(DAYS360(settlement_date,maturity_date)/360,0),-P*R/M, $-\mathrm{P})^{*}(1+. \mathrm{Y} / \mathrm{M})^{\wedge}($ ROUNDUP(DAYS360(settlement_date,maturity_date)/360,0)

-DAYS360(settlement_date,maturity_date)/360)

For example, assume the following transaction using an actual Target Corporation bond (TGT.HG issue):

A US corporate bond with a $\$ 1,000$ par value matures on August 15, 2011 and pays 9.250 percent interest semiannually on August 15 and February 15. The bond is sold on December 18, 2007 to yield an annual market rate of 5.507 percent. ${ }^{11}$

\footnotetext{
${ }^{10}$ As an alternative consistent with bond formula A in Mayle (1993), $\alpha$ can be expressed as one less the number of days between the settlement date and the next interest date (next_interest_date=second_date) divided by the total days in the period $(=1$ DAYS360(settlement_date,next_interest_date)/NOPD.
} 
Using equation (8), the bond's actual price is $\$ 1,153.97$ :

$=$ PV(.05507/2, (ROUNDUP(DAYS360(“12/18/2007”,"8/15/2007”)/180,0),-1000*.0925/2,

$-1000 *(1+.05507 / 2)^{\wedge}($ ROUNDUP(DAYS360(“12/18/2007”,"8/15/2011”)/180,0)

-DAYS360(“"12/18/2007”, “8/15/2011”)/180)

In contrast, using equation (9) and assuming the bond pays 9.250 percent interest annually on February 15, the bond's actual price is $\$ 1,152.09$ :

$=P V(.05507 / 1$, (ROUNDUP(DAYS360(“12/18/2007”,"8/15/2007”)/360,0),-1000*.0925/1,

$-1000 *(1+.05507 / 1)^{\wedge}($ ROUNDUP(DAYS360(“12/18/2007”," $\left.8 / 15 / 2011 ”) / 360,0\right)$

-DAYS360(“12/18/2007”,“8/15/2011”)/360)

\section{SPREADSHEET MODEL}

Equations (8) and (9) can be easily programmed into a single Excel spreadsheet such as illustrated in Figure A which incorporates the Target Corporation bond (semiannual payment) transaction described in the previous section. The spreadsheet is divided into three sections with (1) six inputs in B2:B7 (settlement date, maturity date, par or maturity value, annual stated rate of interest, annual market rate of interest and number of interest periods per year), (2) one primary output in B10 (actual price) and (3) six supporting outputs in B12-B18 (periodic stated rate of interest, periodic interest payment, periodic market rate of interest, number of days in current interest period, number of remaining interest payments after settlement, and fraction of the current period elapsed prior to settlement). For convenience of the reader, the column B output formulas have been placed in column C adjacent to the related output cell.

Figure A

Bond Valuation Spreadsheet Incorporating 30/360 Date Counting

\begin{tabular}{|c|c|c|c|}
\hline & +2 & B & $\mathbf{C}$ \\
\hline 1 & INPUTS: & & \\
\hline 2 & Settlement date (mm/dd/yyyy) & $12 / 18 / 2007$ & \\
\hline 3 & Maturity date (mm/dd/yyyy) & $8 / 15 / 2011$ & \\
\hline 4 & Par or maturity value & $\$ 1,000.00$ & \\
\hline 5 & Annual stated rate of interest & $9.250 \%$ & \\
\hline 6 & Annual market rate of interest & $5.507 \%$ & \\
\hline 7 & Number of interest payments per year ( $1=$ annual; $2=$ semiannual $)$ & 2 & \\
\hline 8 & & & \\
\hline 9 & PRIMARY OUTPUT: & & OUTPUT FORMULAS \\
\hline 10 & Actual price of the bond & $\$ 1,153.97$ & $=\mathrm{PV}(\mathrm{B} 14, \mathrm{~B} 15,-\mathrm{B} 14,-\mathrm{B} 4)^{*}(1+\mathrm{B} 14)^{\wedge} \mathrm{B} 17$ \\
\hline 11 & & & \\
\hline 12 & SUPPORTING OUTPUTS: & & \\
\hline 13 & Periodic stated rate of interest & $4.625 \%$ & $=\mathrm{B} 5 / \mathrm{B} 7$ \\
\hline 14 & Periodic interest payment & 46.25 & $=\mathrm{B} 4 * \mathrm{~B} 13$ \\
\hline 15 & Periodic market rate of interest & $2.754 \%$ & $=\mathrm{B} 6 / \mathrm{B} 7$ \\
\hline 16 & Number of days in current interest period & 180 & $=\mathrm{IF}\left(\mathrm{B} 7=1,360, \mathrm{IF}\left(\mathrm{B} 7=2,180,{ }^{\prime}\right.\right.$ Error' $\left.)\right)$ \\
\hline 17 & Number of remaining interest payments after settlement & 8 & $=$ ROUNDUP(DAYS360(B2,B3)/B16,0) \\
\hline 18 & Fraction of the current period elapsed prior to settlement & $68.333 \%$ & $=\mathrm{B} 17-\mathrm{DAYS} 360(\mathrm{~B} 2, \mathrm{~B} 3) / \mathrm{B} 16$ \\
\hline
\end{tabular}

Several comments about the spreadsheet are helpful. First, the formula for the actual price in cell B10 appears to differ from equation (2). However, this is due to the use of relative cell references for supporting calculations. For example, in equation (2) the periodic interest payment is represented by $-\mathrm{P} \times \mathrm{R} / \mathrm{M}$, whereas in $\mathrm{B} 10$ it

\footnotetext{
${ }^{11}$ Failure to distinguish between the transaction date and settlement date, which can differ by several days, can cause valuation errors. For example, see Rusbarsky and Vicknair (1998) for a discussion of the SEC's T+3 (transaction date plus three) regulation.
} 
is represented by a relative cell reference to $\mathrm{B} 14$, which computes $\mathrm{B} 4 * \mathrm{~B} 13$, where $\mathrm{B} 13=\mathrm{B} 5 / \mathrm{B} 7$. However, together these relative references compute $\mathrm{B} 4 * \mathrm{~B} 5 / \mathrm{B} 7$ which is exactly equivalent to the expression $-\mathrm{P} \times \mathrm{R} / \mathrm{M}$ in equation (2). The goal here is to separately identify the periodic interest rate and periodic interest payment, which some students find difficult to calculate because they fail to distinguish between the stated and market rates and/or convert the annual stated rate into the corresponding periodic rate.

Secondly, in B16, the number of days in the current period (NOPD) is derived from the frequency of interest payments (M) in B7 by a logical IF statement. This allows both semiannual and annual payment bonds to be valued using the same worksheet. Thus, instructors can begin with simple annual payment bonds in a survey course and progress to more complex semiannual payment bonds, including bonds sold between interest payment dates, in a subsequent course using the same spreadsheet model. Of course, this will occur only if the same instructor teaches both courses, or faculty collaborate across and within their respective curriculums (for example, if accounting faculty collaborate with each other and with finance faculty). ${ }^{12}$

\section{CONCLUDING COMMENTS}

Difficulty determining the number of remaining interest payments $(\mathrm{N})$ and the fraction of the current period that has elapsed prior to the settlement date $(\alpha)$ need not present a barrier to studying bond valuation in a realistic setting where bonds may be traded whenever the markets are open. By nesting an appropriate date counting function, such as DAYS360, into the PV function, both the number of remaining interest payments and the fraction of the current interest period that has elapsed prior to the settlement date can be easily inferred from the settlement date, maturity date, and number interest payments per year. Instructors who find the use of DAYS360 too complex, or who use a basic financial calculator without the corresponding day counting function (for example, the Hewlett Packard HP-10BII), may still introduce equation (2) by holding both the settlement date and maturity date to the first (or last day) of the month in which case NOD $=($ Mth2-Mth1 $) \times 30$ and $\alpha=($ Mth2-Mth1) $\times 30 / 180$ or $\alpha=($ Mth2Mth1)×30/360.

\section{REFERENCES}

1. Mayle, J. 1993. Standard Securities Calculation Methods: fixed Income Securities Formulas for Price, Yield and Accrued Interest. Volume 1. $3^{\text {rd }}$ Edition. New York, NY: Securities Industry Association.

2. Rusbarsky, M. \& Vicknair, D. B. (1999). Accounting for bonds with accrued interest in conformity with brokers' valuation formulas. Issues in Accounting Education, 14(2), 233-253.

3. White, M. A. \& Todd, J. M. (1995). Bond pricing between coupon payment dates using a "no-frills" financial calculator. Financial Practice and Education, 5 (Spring/Summer), 148-152.

${ }^{12}$ Sadly, our experience is that such collaboration is not the norm. 